\title{
The great divide: economic complexity and development paths in Brazil and the Republic of Korea
}

\author{
Gustavo Britto, João P. Romero, Elton Freitas \\ and Clara Coelho ${ }^{1}$
}

\begin{abstract}
This paper uses the product space methodology to gain new perspectives on the relationship between economic complexity and economic development, illustrated by case studies of Brazil and the Republic of Korea. It takes import data as an indicator of revealed comparative disadvantage to highlight the relevance of the local market. Product space networks for each decade between 1960 and 2000 are then presented, revealing the significant changes in each country's position in the international division of labour. Lastly, a structural development index is used to measure economic development in each country. The revealed comparative advantage and disadvantage indices indicate that while both countries had similar levels of per capita gross domestic product (GDP) in the early 1960s, the Republic of Korea saw faster growth than Brazil thanks to its early specialization in more complex, technology-intensive goods.
\end{abstract}

\section{Keywords}

JEL classification

Economic development, development models, comparative analysis, productivity, production diversification, economic indicators, Brazil, Republic of Korea

$$
\text { O1, } 02,057
$$

\section{Authors}

Gustavo Britto is Professor in the Department of Economics of the Centre for Regional Development and Planning at the Federal University of Minas Gerais, Brazil. Email: gustavo@cedeplar.ufmg.br.

João P. Romero is Associate Professor in the Department of Economics of the Centre for Regional Development and Planning at the Federal University of Minas Gerais, Brazil. Email: jpromero@cedeplar.ufmg.br.

Elton Freitas is a PhD candidate in the Department of Economics of the Centre for Regional Development and Planning at the Federal University of Minas Gerais, Brazil. Email: eltonfreitas@cedeplar.ufmg.br.

Clara Coelho is a MPhil student in the Department of Economics of the Georg-AugustUniversität Göttingen, Germany. Email: coelhoclaras@gmail.com.

\footnotetext{
The authors gratefully acknowledge the financial support provided by the Foundation for Research of the State of Minas Gerais (FAPEMIG), the Coordination for the Improvement of Higher Education Personnel (CAPES) and the National Council for Scientific and Technological Development (CNPq). This paper won first prize in a competition held by the National Confederation of Industry (CNI) in 2015 for articles on Brazilian industry. The authors are also grateful to an anonymous referee for their valuable comments. The authors alone are responsible for any errors that remain.
} 


\section{Introduction}

The relationship between different economic structures and distinct paths of economic development has long been discussed in economic literature, particularly with the rise of development economics from the 1950s onwards. According to the structuralist literature that flourished in that period, economic development is inextricably linked to changes in the sectoral composition of production (e.g. Lewis, 1955; Kuznets, 1966; Kaldor, 1966; Hirschman, 1958; Prebisch, 1962; and Furtado, 1964); development and growth depend on moving production towards sectors that produce complex goods that have high value added, at the expense of sectors that produce simple, low-value-added goods.

More recently, a number of studies have made the case for an ongoing process of structural change to foster economic development in the long run. These studies identify connections between the sectoral composition of production and the rates of growth in productivity, exports and, ultimately, per capita gross domestic product (GDP). The debate surrounding the dichotomy between the traditional and modern sectors identified in classical and structuralist theories of economic development is rekindled. The new literature highlights the importance of accumulating capabilities to produce more sophisticated goods, arguing that it is a prerequisite for structural change. These capabilities are associated with non-tradable inputs, such as tacit knowledge, and much of the literature on this approach has sought to identify and measure capabilities across countries or industries (e.g. Lall, 1992; Archibugi and Coco, 2005).

In this vein, Hidalgo and others (2007) and Hidalgo and Hausmann (2009) developed a methodology for the empirical analysis of the process of economic development. Instead of directly measuring capabilities, their methodology infers the complexity of a country's productive structure by using the number of goods a country produces with revealed comparative advantage (RCA) (diversity) and the number of countries capable of exporting each good with RCA (ubiquity), which allows the levels of complexity of each product and country to be calculated. These indices are strongly correlated with per capita GDP levels and with faster rates of growth in countries that have managed to move away from traditional, natural-resources-based sectors towards more modern, complex ones (Hausmann, Hwang and Rodrik, 2007; McMillan and Rodrik, 2011).

This methodology has been used to investigate empirically a wide variety of issues related to growth divergence as well as development paths in many other papers, ranging from case studies and cross-country studies, which show that economic complexity are strongly correlated with technological capabilities, to evaluations that use subnational data to highlight the importance of geographical location. A common thread that runs through the empirical studies is that structural change is fundamental for economic development, which has led analysts to re-examine the structuralist ideas put forward by ECLAC through the lenses of capability and complexity (Gala, Camargo and Freitas, 2017).

Studies that use this methodology have, given its origins, focused solely on the exports side of international trade. While they are very useful, indicators based on exports fail to take into consideration the impact of the local market on structural change and economic development. Depending on a country's size, factor endowments, trade openness, import requirements and finished or semi-finished goods may play as important a role as exports in promoting or hindering structural change and growth. However, the methodology can also be used to investigate development processes empirically over time. The methodology can be adapted to comparative studies, by taking into account changes in the international division of labour and thus in the composition of international trade in the last 50 years, as well as the effects of absolute levels of key variables, such as those related to country size, together with relative measures, such as relative advantages.

To address these issues empirically, this article applies the economic complexity methodology to a comparative analysis of Brazil and the Republic of Korea. The article's contribution to the existing literature is threefold. First, it analyses how the structure of production and trade has changed over 
time by using trade data to construct product networks for each decade. Secondly, it evaluates the role played by the local market by compiling an index of revealed comparative disadvantage (RCD) based on import data: a decrease in the number of industries with RCD indicates a more competitive domestic productive sector. Lastly, it proposes replacing the economic complexity index with a structural development index in order to calculate the economic development of a country's productive structure.

Section II of this article discusses the theoretical framework and shows the evolution of the product space from 1965 to 2005. Section III examines the transformation of productive structures in Brazil and the Republic of Korea. Section IV provides some final thoughts.

\section{Product and economic complexity}

\section{Revealed comparative advantage, diversification and ubiquity}

As part of their investigation into the relationship between economic structures and economic growth, Hidalgo and others (2007) looked at whether a country's productive structure influences the path, cost and speed of change towards producing sophisticated goods. They found that the production of different types of goods requires different sets of capabilities. Consequently, a country's capabilities dictate the types of goods it can competitively produce and how difficult it is for that country to broaden its range of goods to include those that require different, or additional, capabilities. Conversely, the diversity and complexity of these goods indicates the extent of a country's capabilities.

To calculate how efficiently each economy produced each product, Hidalgo and Hausmann (2011) use the revealed comparative advantage (RCA) index developed by Balassa (1965):

$$
R C A_{j k t}=\left(\frac{X_{j k t} / \sum_{k} X_{j k t}}{\sum_{j} X_{j k t} / \sum_{j} \sum_{k} X_{j k t}}\right)
$$

where $x$ are the exports of product $k$ from country $j$ at time $t$. A higher RCA index indicates that the production of a given product in that country is more competitive. A lower index indicates that the opposite is true.

Hidalgo and others (2007) also examine the proximity between goods by using conditional probabilities to establish how close to each other different products are in terms of the capabilities. This is based on the assumption that a country is more likely to produce and export two products if their production requires similar capabilities. The authors use trade data from UN Comtrade, which are highly disaggregated and cover a high number of countries and years, to calculate the probability of a country exporting product $i$ with RCA given that it exports product $k$ with RCA. Lastly, the authors map the product space by identifying linkages between goods based on their proximity.

Using the product space, Hidalgo and others (2007) show that less developed countries tend to produce goods with fewer linkages, which makes it difficult for these countries to diversify their production towards more sophisticated goods. The opposite is true of developed countries. These findings point to three important conclusions: (i) different productive structures and their associated capabilities create very different opportunities for boosting economic growth; (ii) for this reason, economic growth is path dependent; and (iii) diversifying towards sophisticated goods is time consuming, as new capabilities must be created and less sophisticated goods are not linked to many other activities. 
To complement this approach, Hidalgo and Hausmann (2011) propose two additional indicators of product and economic complexity:

$$
\begin{aligned}
& D_{j t}=\sum_{k} N_{j k t} \\
& U_{k t}=\sum_{j} N_{j k t}
\end{aligned}
$$

where $D$ denotes diversification, $U$ denotes ubiquity and $N=1$ if country $j$ exports product $k$ with RCA at time $t$, and $N=0$ otherwise. Diversification is the number of products that a country exports with RCA, while ubiquity is the number of other countries that export those products with RCA. Thus, the more diverse a country's exports are, the more complex its economy is. In contrast, if a product is less ubiquitous, the economy is more complex.

Hidalgo and Hausmann (2009) and Felipe and others (2012) use these indicators to show that growth is higher in those economies that have higher product diversification, producing less common goods. It should therefore not be a surprise that Felipe and others (2012) find that economic and product complexity are closely associated with the accumulation of technological capabilities, as measured in Schumpeterian works such as Archibugi and Coco (2005). The conclusion is that, in general, diversification is correlated positively with income levels and negatively with ubiquity.

These indices can therefore be merged to measure and compare the sophistication of products and countries' economies. On the one hand, a country will have a more sophisticated economy if the goods it produces are highly diverse and less ubiquitous. On the other hand, a product will have a higher degree of sophistication if it is less ubiquitous and produced by more diversified countries. Formally:

$$
\begin{aligned}
& E S_{j t}=\left(\frac{1}{\sum_{k} N_{j k t} U_{k t}}\right) D_{j t} \\
& P S_{k t}=\left(\frac{1}{U_{k}}\right) \sum_{j} N_{j k t} D_{j t}
\end{aligned}
$$

where $E S$ and $P S$ stand for economic sophistication and product sophistication, respectively.

The indices shown above have been used to analyse a wide range of issues related to the link between economic complexity and economic growth in studies ranging from case studies to econometric investigations using national and subnational data. Felipe, McCombie and Naqvi (2010) argue that Pakistan's inability to produce more sophisticated goods has resulted in persistent balance-of-payments problems, reducing its growth rates. China, on the other hand, grew much faster because of sustained increases in the RCA of highly complex products such as machinery and electronic goods (Felipe and others, 2013). Boschma, Balland and Kogler (2013) examines the connections between technological proximity and technological change. Using patent data from the United States Patent and Trademark Office, the authors show that technological capabilities are linked to different trajectories of technological specialization in cities across the United Sates. In turn, Bahar, Hausmann and Hidalgo (2014) use measures of relative comparative advantages and of export similarity to evaluate how geographic proximity influences productive specialization. They show that neighbouring countries tend to have RCAs in similar products, most likely as a result of knowledge diffusion. Moreover, Romero and Britto (2018) investigate whether productive sophistication can explain not only productivity growth but also the size of income elasticities of trade in different technological sectors. 


\section{Revealed comparative disadvantage, bottlenecks and potential industries}

While this basic methodology is being used more widely, to date studies have tended to focus exclusively on export data. Consequently, the analyses cover issues related to the competitiveness of a country's exports. As a result, very little consideration has been given to the local market. This gap in the literature can be filled using the rich data available on countries' imports. That data can be used to create indices of revealed comparative disadvantage (RCD), which are calculated analogously and can be analysed in conjunction with the RCA index.

Formally:

$$
R C D_{j k t}=\left(\frac{m_{j k t} / \sum_{k} m_{j k t}}{\sum_{j} m_{j k t} / \sum_{j} \sum_{k} m_{j k t}}\right)
$$

where $m$ denotes imports of each good $k$ for the country $j$ at time $t$.

This measure captures the relative import needs of the local economic structure. If $R C D>1$, the country's dependence on imports of good $k$ is higher that the relevance of the good in the international trade, while if $R C D<1$, the country is not an effective importer, meaning that it has a relatively small competitive disadvantage. Interestingly, when there is no RCA in the production of a given good $k$, there is a demonstrably important local market for this good. As Dornbusch, Fischer and Samuelson (1977) show, in theory, a country might produce goods in which it has a comparative disadvantage if transport costs or tariffs are large enough. However, it is also possible that some intermediate products are not imported because domestic production is too weak to use them, or because domestic income levels do not generate enough demand for them.

Thus, in parallel to the export diversification index $D$, an index can be developed to indicate the size of the bottlenecks $(B)$ :

$$
B_{j t}=\sum_{k} M_{j k t}
$$

where $M=1$ if country $j$ imports product $k$ with RCD at time $t$, and $M=0$ otherwise.

These indices allow us to evaluate how domestic production is performing in the local market and, more importantly, to see whether industries without RCA have the potential to export, or whether they are losing competitiveness and becoming industries with RCD.

\section{The development trajectory of Brazil and the Republic of Korea}

The aforementioned indices, together with the graphical analysis of the product space over time, are valuable tools to evaluate the very distinct paths of economic development in Brazil and the Republic of Korea over the past 50 years. These two countries are very different in terms of culture, history, natural resource endowments, area and population size. Nonetheless, as figure 1 shows, they shared a similar path of per capita GPD until 1980. Until then, Brazil's per capita GDP was considerably higher than that 
of the Republic of Korea, and both were growing at similar rates. However, after 1980, Brazil followed a path of economic stagnation, while the per capita GDP of the Republic of Korea continued to grow, reaching a level compatible with that of developed countries by 2010.

Figure 1

Brazil and the Republic of Korea: per capita GDP, 1960-2014

(Thousands of constant 2010 US dollars)

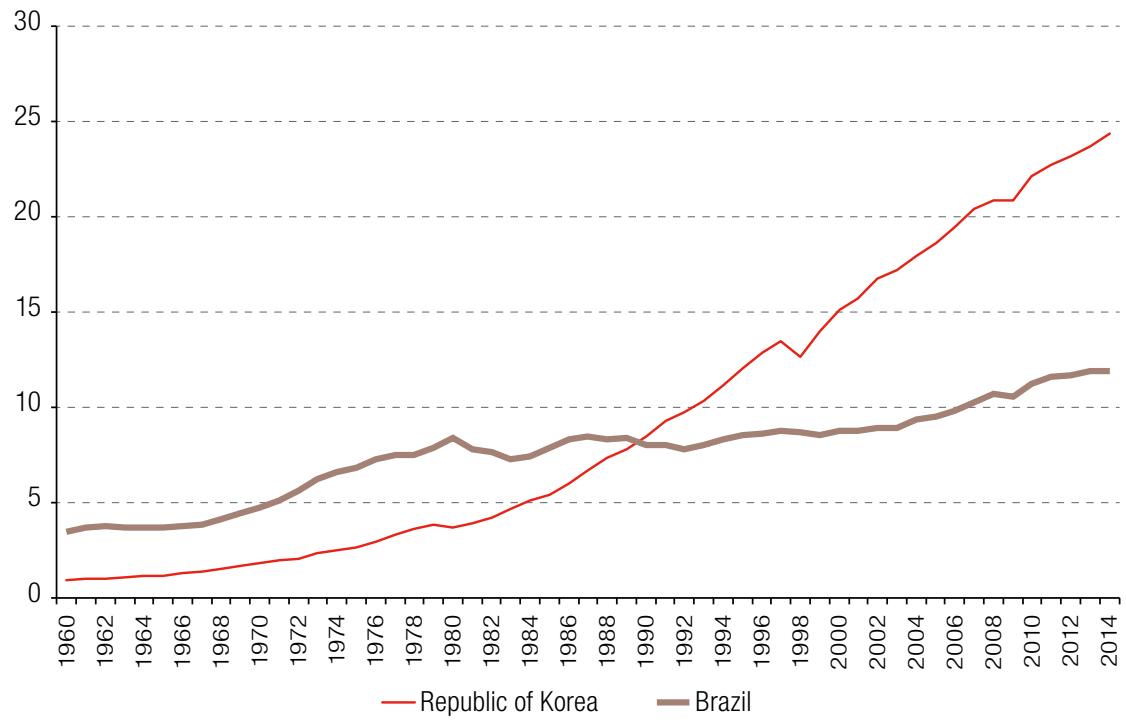

Source: World Bank, World Development Indicators.

The trends shown in figure 1 explain why these two countries have been popular choices for comparative studies since the 1980s, as they illustrate how different policy choices in Asia and Latin America have, over the decades, led to contrasting realities.

It can be argued that apart from their per capita GDP growth rates prior to 1980, Brazil and the Republic of Korea have little in common. Every other socioeconomic indicator reveals differences rather than commonalities. Consideration should therefore be given to how those different characteristics under distinct circumstances have led to such divergent trends in terms of structural change and how that change is related to the complexity of the goods produced in each country.

To analyse the development of the productive structures of Brazil and the Republic of Korea between 1962 and 2010 using the methodology described in the previous section, trade data was gathered from UN Comtrade, disaggregated to the four-digit level of the Standard International Trade Classification (SITC), Revisions 1 and 2. This classification comprises 613 products in Revision 1 and 784 products in Revision 2. Both revisions are used here, with revision 2 utilized whenever possible; however, as revision 1 covers the period from 1962 to 1973 in some cases that revision had to be used for the purposes of making comparisons across the whole period under consideration. Industries were divided into 6 technological sectors, following the classification proposed by Lall (2000): (i) primary products, covering 135 industries in revision 1 and 148 industries in revision 2; (ii) resource-based manufactures, covering 187 industries in revision 1 and 197 industries in revision 2; (iii) low-technology manufactures, covering 128 industries in revision 1 and 161 industries in revision 2; (iv) medium-technology manufactures, covering 113 industries in revision 1 and 202 industries in revision 2; (v) high-technology manufactures, covering 38 industries in revision 1 and 66 industries in revision 2; and (vi) other manufactures, covering 12 industries in revision 1 and 10 industries in revision 2. 
Table 1 shows the average product complexity of each technological sector and reveals a clear correlation between the technological content of each industry and the level of complexity of its production. This justifies the decision to divide the industries according to Lall's (2000) technological classification, since a process of structural change towards high-technology industries can also be interpreted the country's productive structure becoming increasingly complex.

Table 1

Average product complexity by technological sector

\begin{tabular}{cccccc}
\hline Primary products & Resource-based & Low-technology & Medium-technology & High-technology & Other manufactures \\
\hline-0.711 & -0.230 & 0.205 & 0.714 & 0.806 & 0.120 \\
\hline
\end{tabular}

Source: Prepared by the authors.

\section{Trade diversification and economic development over the last 50 years}

As expected, the structural changes in Brazil and the Republic of Korea were the result of circumstances and economic policies. Figure 2 shows the number of industries with RCA by technological sector in Brazil and the Republic of Korea, thus charting the evolution of productive diversification in those countries. It conveys four important pieces of information. First, as expected, Brazil has always been more competitive in primary products than the Republic of Korea, while the latter has always been more competitive in low-technology manufactures than Brazil. Secondly, from 1978 onwards, Brazil has focused on increasing the competitiveness of its resource-based manufactures, while the Republic of Korea has focused on low-technology manufactures. Thirdly, diversification in medium-technology manufactures is, in general, similar in both countries throughout the period under consideration. Finally, there are considerably more high-technology manufactures with RCA in The Republic of Korea.

Figure 2

Trade diversification by technological intensity, 1962-2009

(Number of industries with revealed comparative advantage)

\section{A. Brazil}

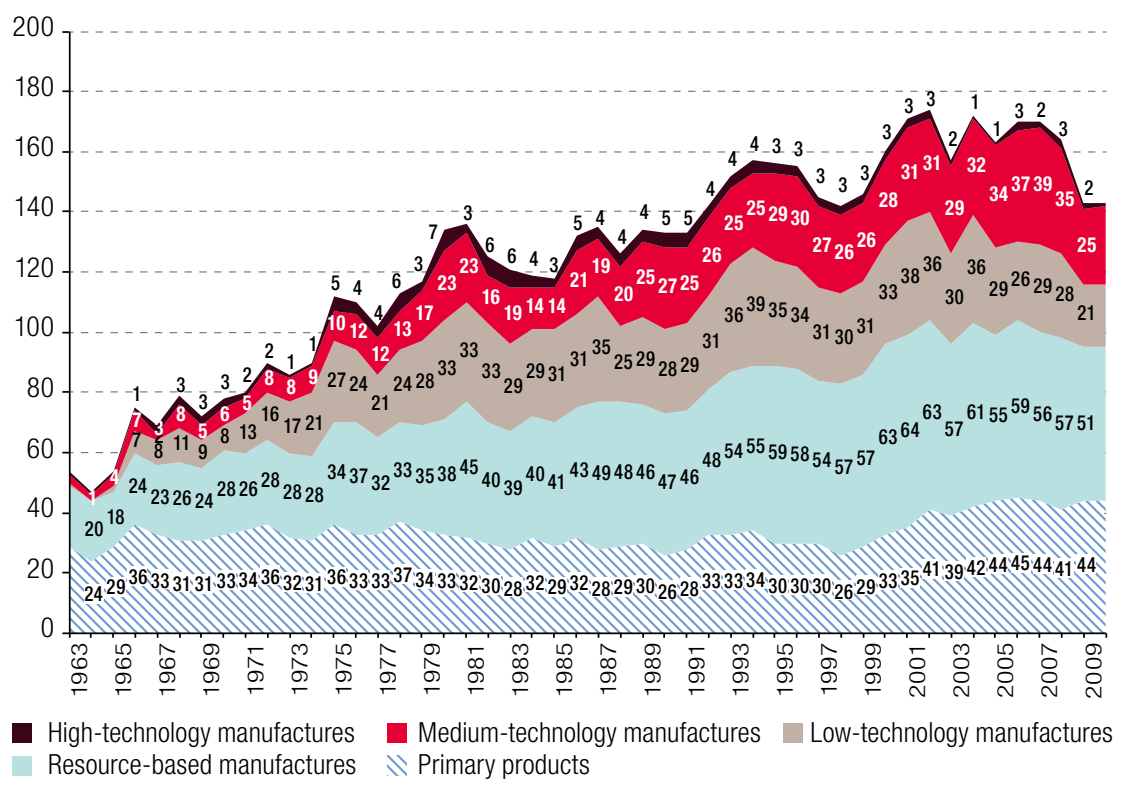


Figure 2 (concluded)

\section{B. The Republic of Korea}

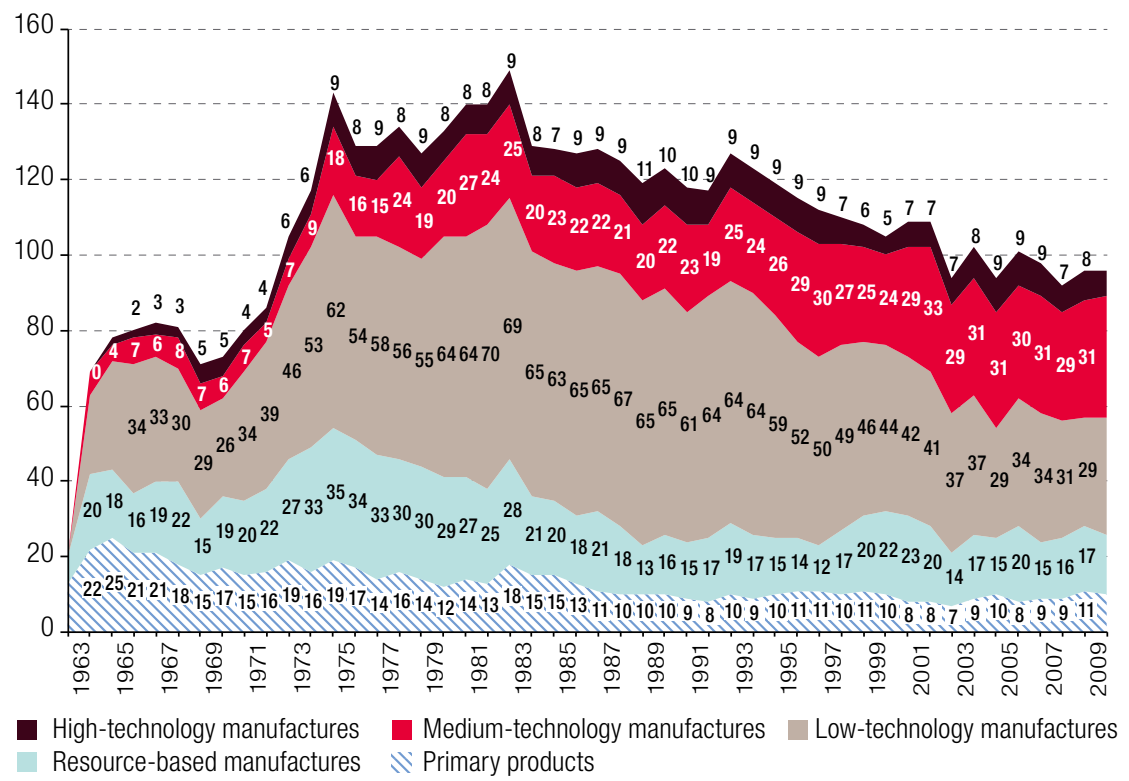

Source: Prepared by the authors.

Note: Standard International Trade Classification (SITC), Revision 1, at the four-digit level was used for the whole period.

Brazil already had a considerable number of industries specializing in primary products and resource-based manufactures with RCA in 1960. Heavy industries had been created and supported during the period from 1930 to 1950, and automobile and communication industries sprang up in 1955. From 1964 to 1973, Brazil saw growth of over 8\% per year, based on import substitution industrialization. However, with the first oil crisis in 1973, Brazil started to experience balance-of-payment difficulties, which led the military government to step up import substitution industrialization, increasing the domestic production of intermediate inputs and machinery (Burlamaqui, de Souza and Barbosa-Filho, 2006, p. 11).

In the 1980s, after the second oil crisis, Brazil's growing foreign debt forced a recessive adjustment and the country eventually defaulted on its payments in 1986. That decade was marked by slow growth and hyperinflation. The 1990s saw a process of rapid economic liberalization and privatization; however, Brazil was only able to beat hyperinflation in 1994 following monetary reforms. During these two decades, the average GDP growth rate was just over 2\% (Netto, 2005). Growth rates only began to recover after 2004, averaging around $4 \%$, thanks to a period of economic stability, an uptick in State investment and the adoption of policies that fostered wage increases and income distribution, boosting the domestic market (Serrano and Summa, 2011). Figure 2 indicates that the liberalization of the Brazilian economy that took place from 1994 onwards led to a process of "reprimarization".

In contrast, the Republic of Korea had about half as many industries with RCA as Brazil in the 1960s. The period from 1963 to 1972 marked the beginning of an industrialization effort, which initially focused on developing basic institutions to support the adoption of foreign technology. In that period, the governments of the Republic of Korea formulated a series of five-year plans for economic growth. The objective of the first two plans was to build an industrial base, increase energy production and encourage companies to invest in technology acquisition (Hong, Jeon and Kim, 2013; Kuznets, 1990; Collins, 1990).

The chaebols, family-run conglomerates, were concentrated in the production of low-technology manufactures during the 1960s, moving into heavy medium-technology manufactures and high-technology 
manufactures industries, in particular the chemical, naval, automobile and machinery industries, during the 1970s (Jacobsson, 1993; Woo-Cumings, 1999). The number of high-technology manufacturing industries with RCA did not change significantly in the 1960s, but their share of exports grew in the 1980s, demonstrating the gains the economy had made in terms of competitiveness. While the number of industries with RCA in Brazil was around 100 in 1974, there were already some 150 in the Republic of Korea.

Political reforms were undertaken in the Republic of Korea in the 1980s that profoundly changed the State's relationship with chaebols' labour unions (Chang, 2006). These changes led to: (i) a shift in industry policies to provide more functional support to manufacturing; (ii) attempts to promote small and medium enterprises; (iii) financial liberalization; and (iv) trade liberalization with the introduction of a tariff that abolished exemptions for strategic industries in 1984 (Harvie and Lee, 2003).

Lastly, the Republic of Korea was affected by the Asian financial crisis in the late 1990s but was able recover quickly. As a result of that crisis, steps were taken to regulate the financial system through changes to corporate governance, which improved the feasibility of the banking sector and reduced the diversification of chaebols by eliminating subsidies and concentrating them by specialization (Haggard, 2000). The chaebols also became less diverse following the decision to lift restrictions on foreign competition, a process that started in the 1980s and was consolidated during the 1990s.

\section{Changes in product space over time}

The trends in trade diversification set out above reflect the structural changes that took place in both countries. To illustrate how the structures of world production and trade have changed over time, a product space was constructed for each decade of the period under consideration (see figure 3). Changes in this network are associated with the evolution of the international division of labour, which are reflected in shifts in international trade. The first two product spaces show the long-term changes that took place at the global level between 1965 and 2005. The last three product spaces show the progressive changes over that period, by providing snapshots of each decade, 1975, 1985 and 1995, respectively.

As can be seen, the shape of the network for 2005 is the same as the one constructed by Haussmann and others (2011). However, this article classifies products using the technology categories developed by Lall (2000), instead of those introduced by Leamer (1984) used by Hidalgo and others (2007). Lall's classification provides more information about the characteristics of simple and sophisticated products.

In the product space for 2005, high- and medium-technology goods are positioned to the centre-left, which corresponds to electronic and chemical products on the network constructed by Haussmann and others (2011). Low-technology, resource-based and primary products are generally located to the centre-right of that product space, with the latter also positioned on the fringes of the network. A distinct node of low-technology products (garments) is visible on the centre-right of the network, surrounded by other low-technology and primary goods.

The product space for 1965 is concentrated around a large central node, formed mostly of high-, middle- and low-technology goods. A more disperse ring of those same goods appears around the central node, with low-technology goods spilling over to the lower left-hand side. Resource-based and primary products are found on the fringes of the network, particularly the upper left-hand side. This structure is consistent with a marked division of labour and trade between primary and manufactured goods. In addition, this radial geography of the product space in terms of technological intensity is suggestive of a centripetal path of development through successive waves of industrial upgrades from resource-based production towards higher technology, more complex goods in the middle. 
Figure 3

World: product space by technological intensity, 1965-2005

1965

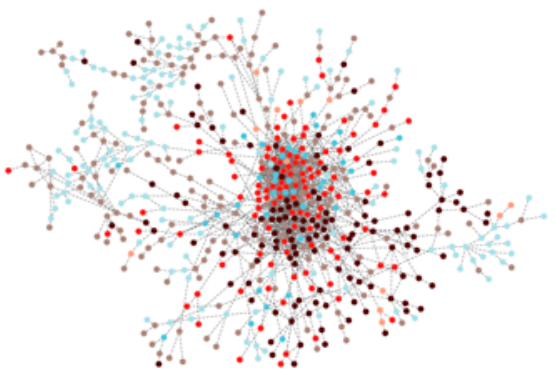

1985

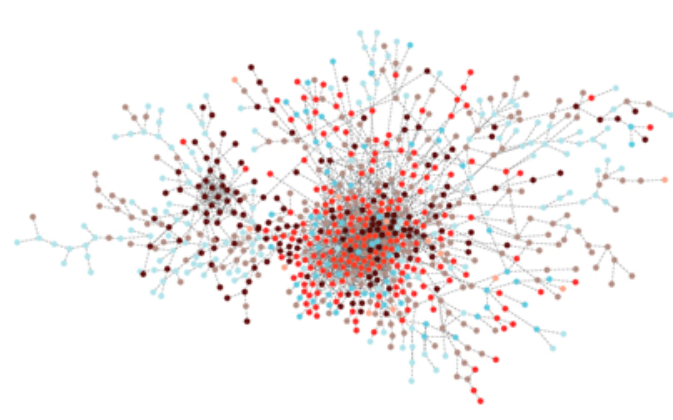

2005

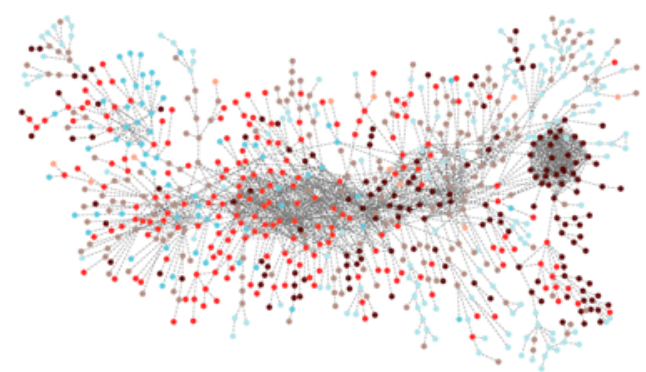

1975

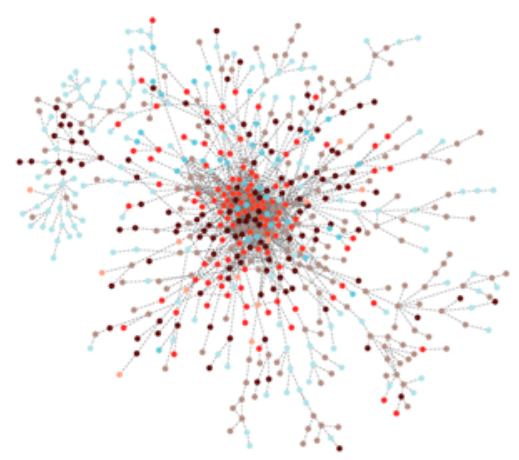

1995

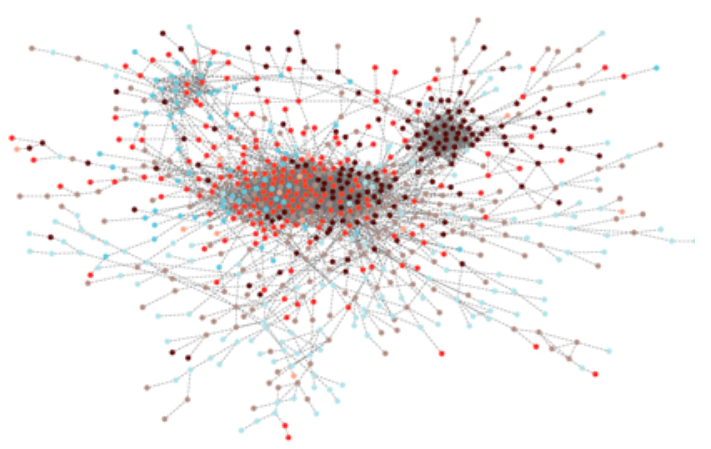

Source: Prepared by the authors.

Note: Product spaces for 1965 and 1975 were calculated using Standard International Trade Classification (SITC), Revision 1, at the four-digit level, while those for 1985, 1995 and 2005 used Standard International Trade Classification (SITC), Revision 2, at the four-digit level.

All the networks were constructed using the maximum spanning tree method, under which a threshold must be set for the proximity between nodes to allow for a meaningful visualization of the links between them. This threshold decreases markedly for the product spaces over the period under consideration: to plot the network for 1965, the threshold was set at 0.70; for 1975 and 1985 it was 0.65; and for 1995 and 2005 it was 0.55 . These calibration changes indicate shifts in international trade 
patterns and country specializations, and that the probability of co-exporting a number of goods was much higher in the 1960s, which suggests that international trade was more concentrated in terms of value and more segmented in terms of sectors.

During the period under consideration, exported goods became increasingly diverse less developed countries began to account for a larger share of international trade. Meanwhile, product differentiation and complexity increased steadily, thanks to continuous technological developments in more advanced countries. As expected, the product space changes accordingly; the network becomes more elongated from one decade to the next, and goods are more clearly grouped according to technological intensity. The notional development path becomes a long U-shaped curve, as complex products move further away from simpler ones, suggesting a very distinct international division of labour and very low probabilities that such distinct products would be co-exported.

The changing shape of the network shows the importance of considering products' technological intensity in addition to more traditional resource-based classifications. As is clear from figure 3, exports have become increasingly segmented in terms of technological intensity over the course of the period under consideration, with a line leading from low-technology goods, on the right-hand side, though medium-technology ones in the middle, to high-technology products on the left-hand side in the network for 2005.

\section{Revealed comparative advantages and disadvantages}

After examining the evolving product space and the changing economic structures in Brazil and the Republic of Korea, the next step is to analyse changes in comparative advantages in each country during the period under consideration. These changes reveal how productive competitiveness together with relative trade advantages and disadvantages are linked to the level of complexity —indicated by technological intensity - of goods traded.

The global product space is used to show how the productive structures of Brazil and the Republic of Korea have evolved, (see figures 4 and 5, respectively). In 1965 the productive structure of the Republic of Korea was already more focused on low-technology products, while Brazil was producing mostly primary products. This is an important finding, as other comparative literature unanimously focuses on the late 1970s and early 1980s as the point when the economic development of the two countries diverged.

The networks for 2005 show that the Brazilian productive structure has become more diversified, with a considerably larger number of industries with RCA across all sectors, but primary products and resource-based and medium-technology manufactures still made up the lion's share of Brazilian exports. Meanwhile, the number of primary and low-technology industries fell sharply in the Republic of Korea, offset by marked increases in the medium- and high-technology industries.

Figure 6 shows the share of each technological sector in the total exports of Brazil and the Republic of Korea, revealing a striking difference between the export structures of the two countries. On the one hand, Brazil had failed to reduce the share of both primary products and resource-based manufactures below $50 \%$ of total exports, while medium- and high-technology manufactures accounted for only $25 \%$ and $7 \%$ of total exports in 2009 , respectively. On the other hand, the share of both primary products and resource-based manufactures fell to $8 \%$ of total exports of the Republic of Korea in that same year, while medium- and high-technology manufactures accounted for $44 \%$ and $29 \%$ of total exports, respectively. 


\section{Figure 4}

Brazil: revealed comparative advantages and productive diversification by technological intensity, 1965-2005

1965

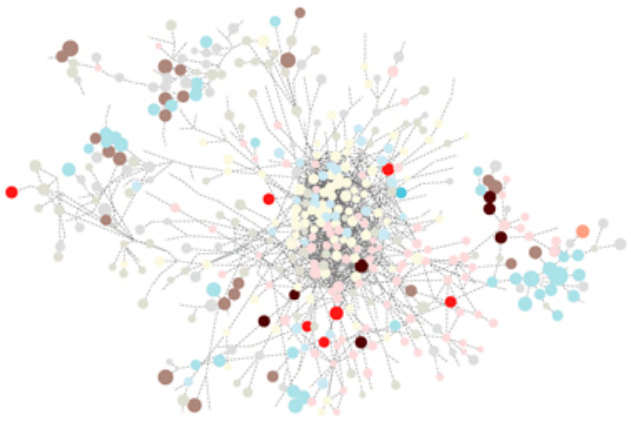

1985

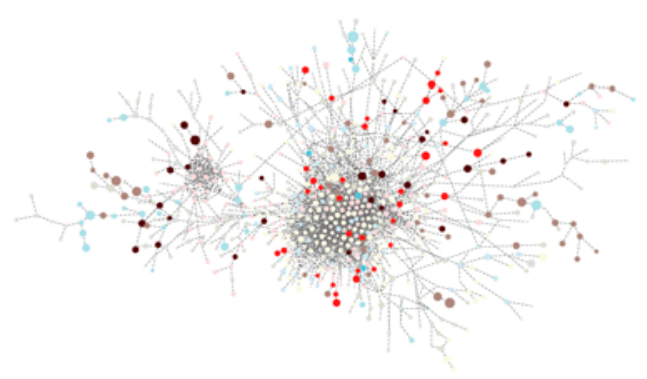

2005

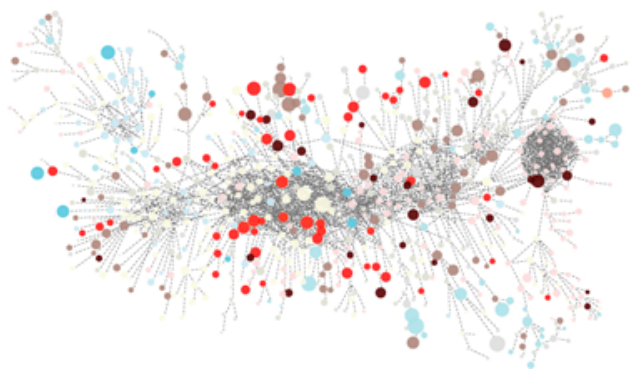

1975

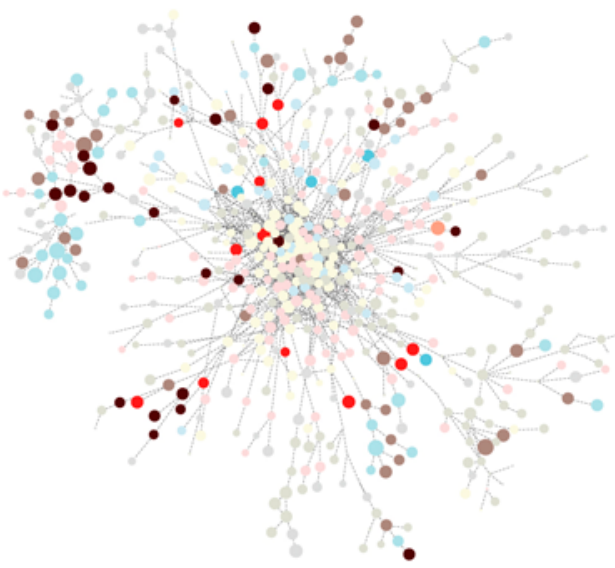

1995

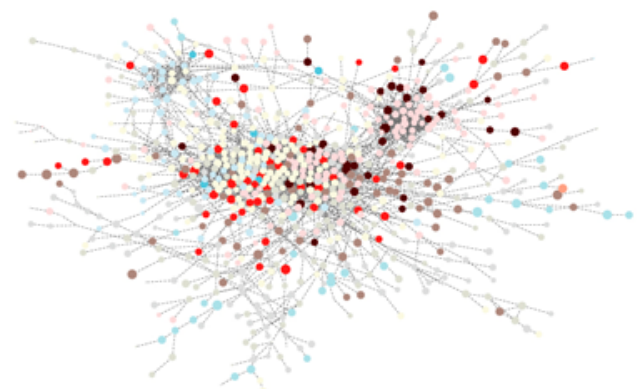

Source: Prepared by the authors. 


\section{Figure 5}

The Republic of Korea: revealed comparative advantages and productive diversification by technological intensity, 1965-2005
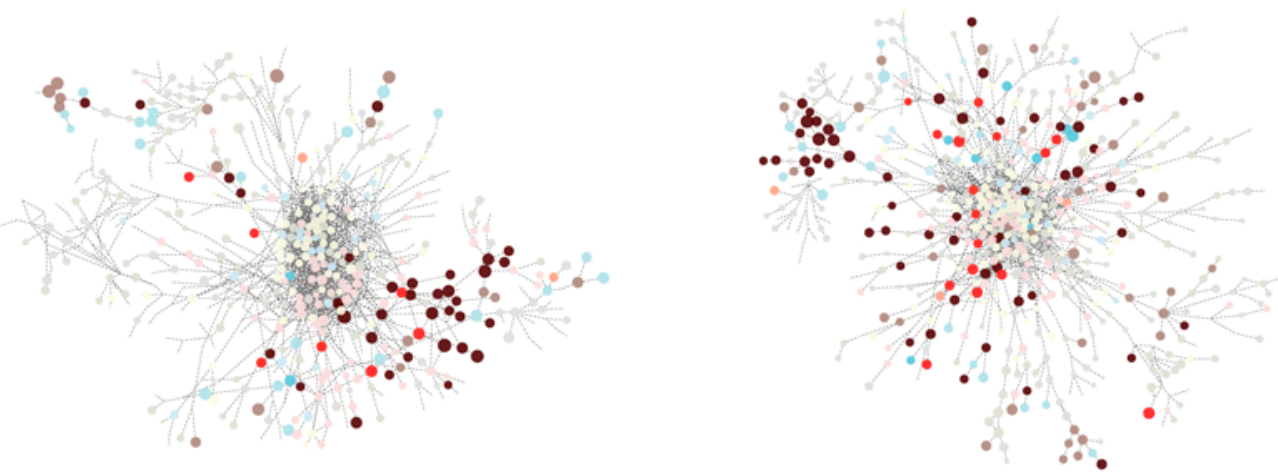

1985

1995
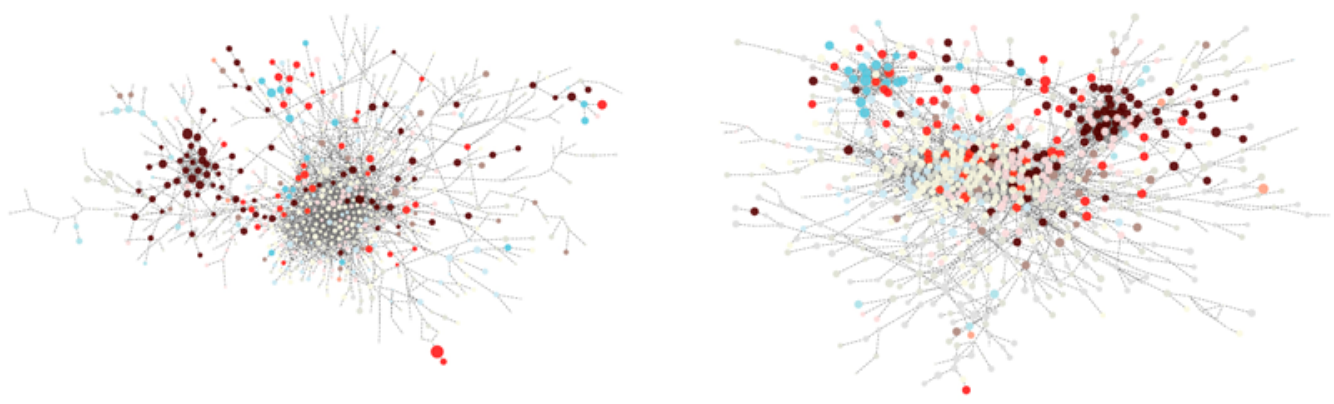

2005

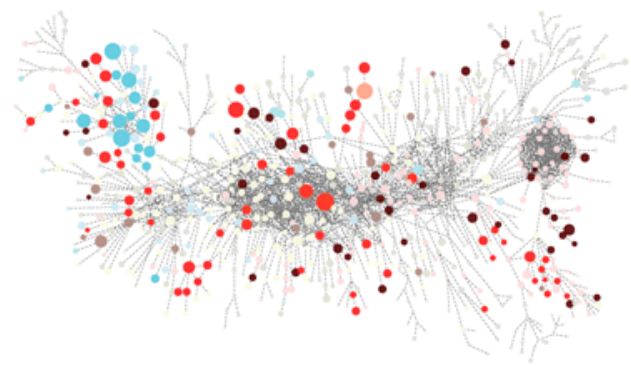

Low-technology manufactures

Medium-technology manufactures

nesource-based manufactures

Primary products

High-technology manufactures

Other manufacturing products

Source: Prepared by the authors. 
Figure 6

Share of exports by technological intensity, 1962-2009

(Percentages)

\section{A. Brazil}

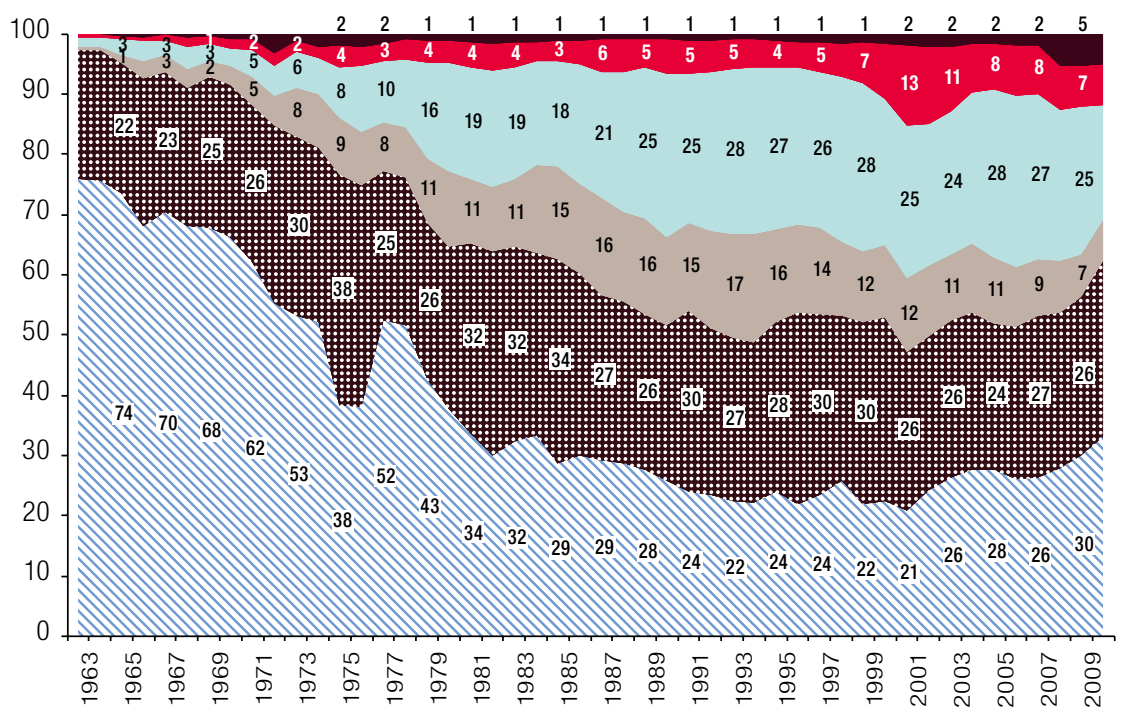

B. The Republic of Korea

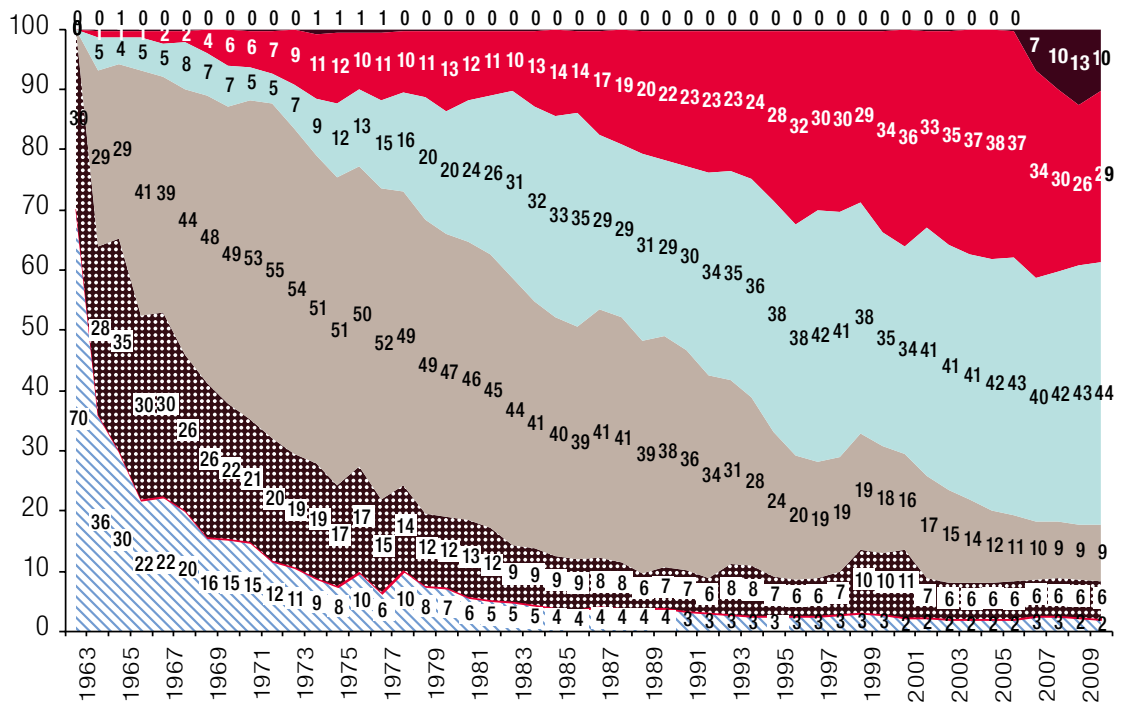

Other manufacturing products Low-technology manufactures

High-technology manufactures $\square$ Medium-technology manufactures
Resource-based manufactures $N$ Primary products

Source: Prepared by the authors.

Note: Standard International Trade Classification (SITC), Revision 1, at the four-digit level was used for the whole period.

Figure 6 indicates that low levels of diversification are not a problem if medium- and high-technology manufactures account for a sufficiently large share of exports; the number of industries with RCA is not as important as the share of those exports.

Analysis of how bottlenecks in the productive structures of Brazil and the Republic of Korea have evolved reveals five important pieces of information (see figure 7). First, Brazil has always been less competitive in medium- and high-technology manufactures than the Republic of Korea. Second, 
Brazil and the Republic of Korea have had a similar number of bottlenecks in primary products and resource-based manufactures. Third, the number of bottlenecks in Brazil fell between 1980 and 1986 a result of the considerable decrease in the country's imports following the external adjustment that the economy underwent after the 1979 oil crisis. Fourth, the number of bottlenecks in primary products and resource-based manufactures sectors increased in the Republic of Korea after 1985. Lastly, from 2002 onwards the bottlenecks in primary products decreased in both economies.

Figure 7

Bottlenecks by technological intensity, 1962-2009

A. Brazil

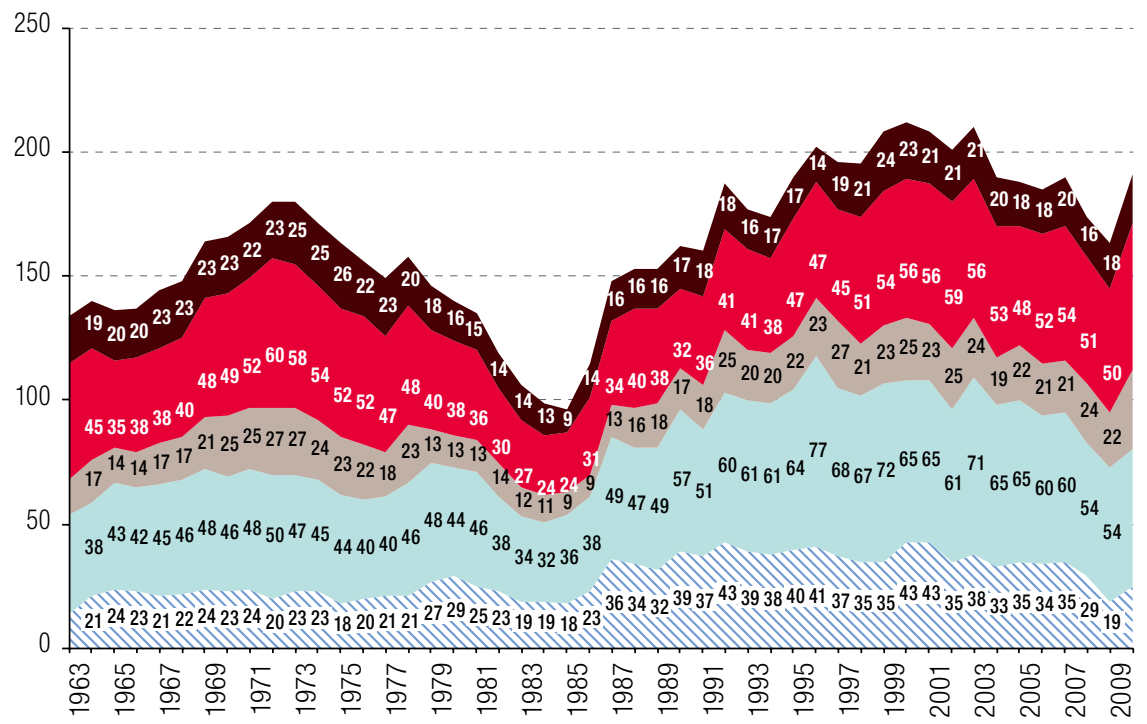

B. The Republic of Korea

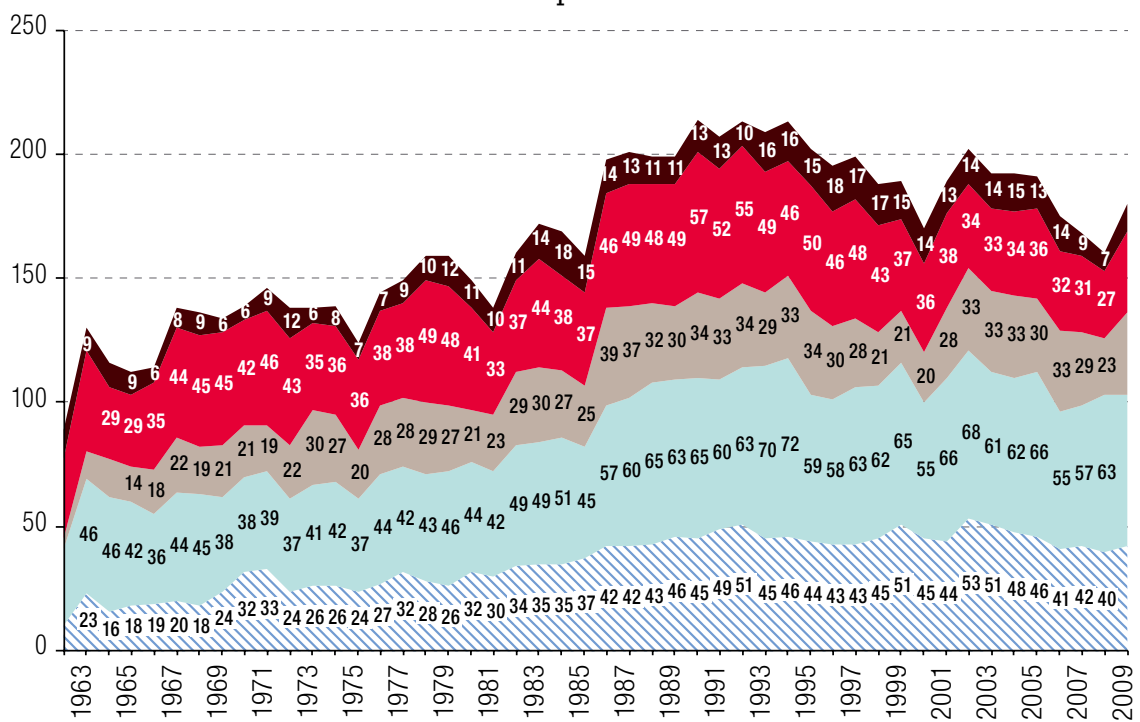

High-technology manufactures Resource-based manufactures

Medium-technology manufactures Low-technology manufactures

Primary products

Source: Prepared by the authors.

Note: Standard International Trade Classification (SITC), Revision 1, at the four-digit level was used for the whole period. 
Figures 8 and 9 illustrate the evolution of RCD over the period under consideration in Brazil and the Republic of Korea, respectively. The networks for 1965 show that bottlenecks in the productive structures of Brazil and the Republic of Korea were similar at that time. The main import needs of both countries were concentrated in resource-based and medium-technology industries, followed by high-technology industries. By 2005, however, the product space shows that the Republic of Korea has reduced its import needs in medium-technology industries (in the centre of the network), while imports of primary products have risen (on the periphery of the network). Whereas, in Brazil, the distribution remained largely the same, with a slight increase in medium-technology industries.

\section{Figure 8}

Brazil: revealed comparative disadvantages by technological intensity, 1965-2005
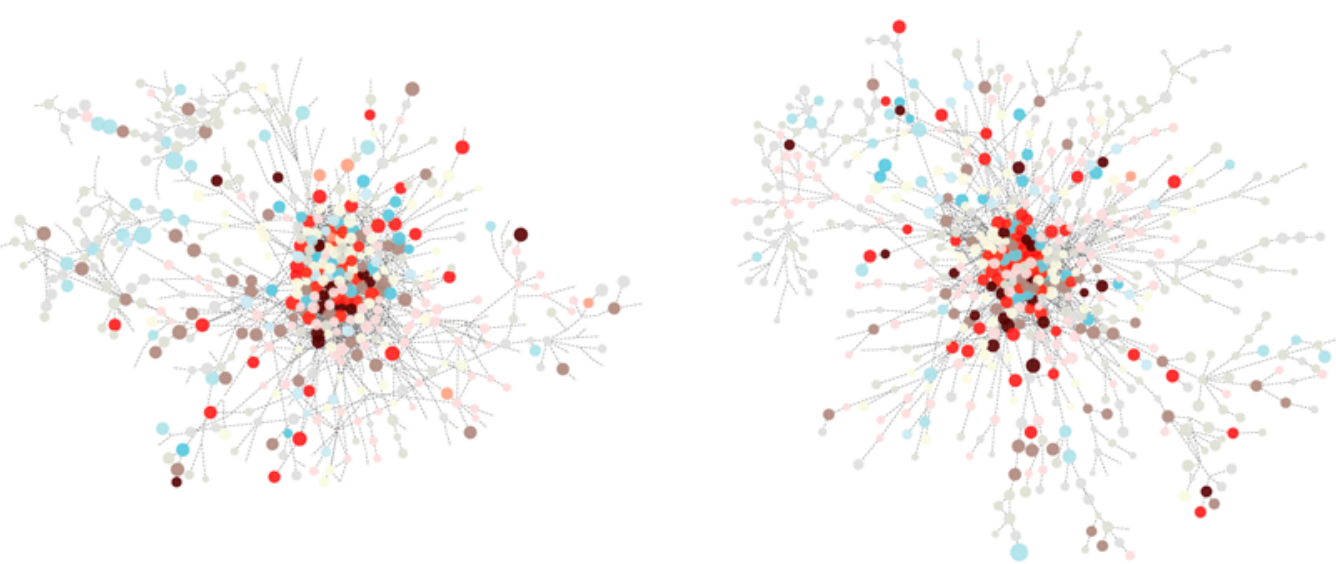

1985
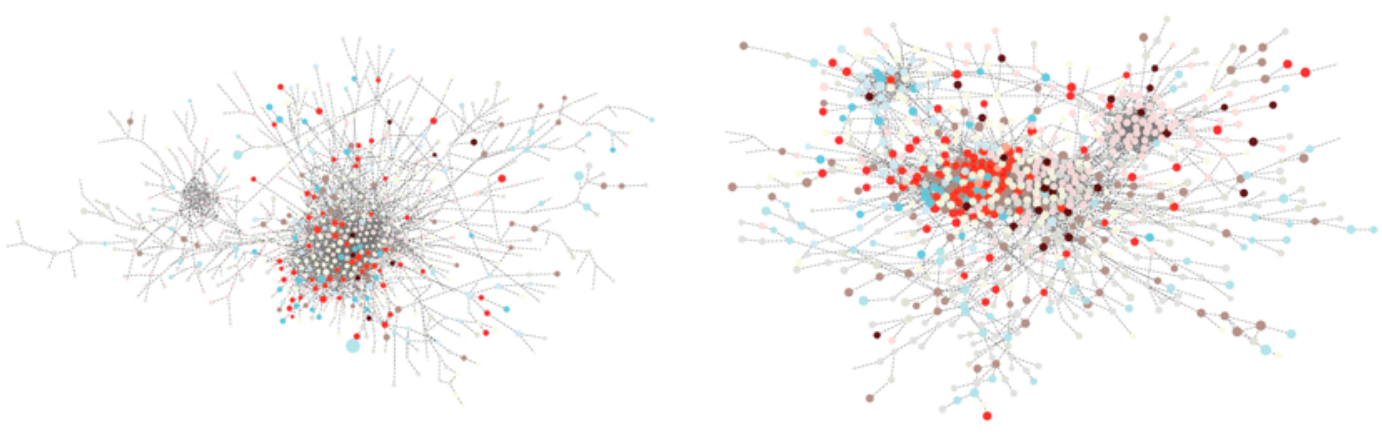

2005

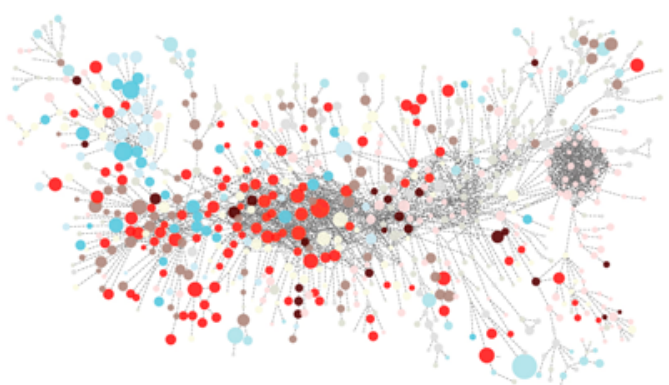

Low-technology manufactures

Medium-technology manufactures

Resource-based manufactures

Primary products

High-technology manufactures

- Other manufacturing products

Source: Prepared by the authors. 


\section{Figure 9}

The Republic of Korea: revealed comparative disadvantages by technological intensity, 1965-2005

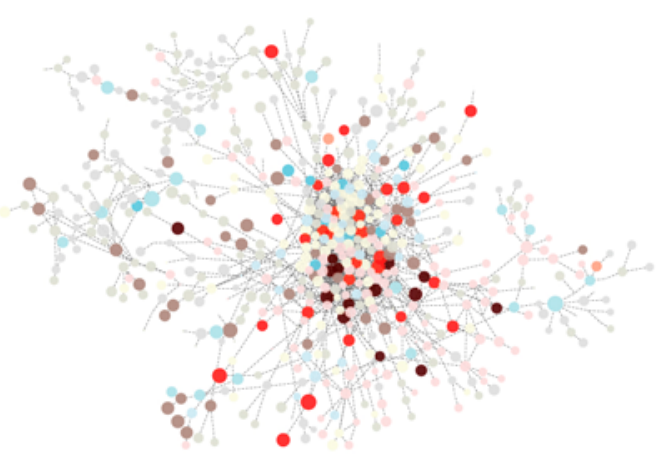

1985

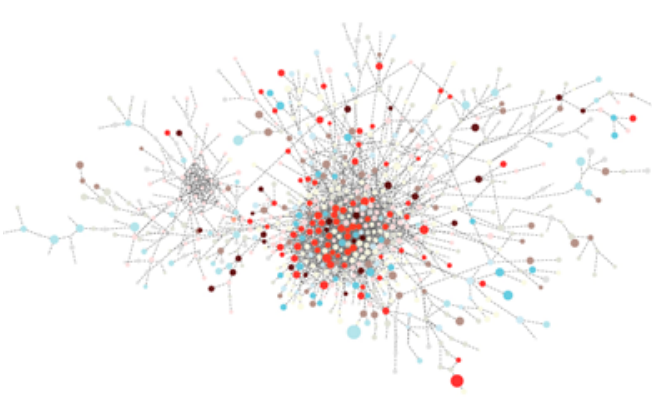

2005

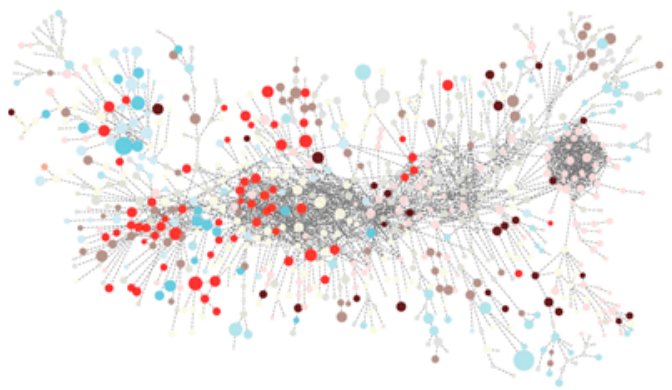

Source: Prepared by the authors.

Figure 10 shows the share of imports from each sector in the total imports of Brazil and the Republic of Korea, and reveals that the import structure of the two countries is, in fact, very similar, with only two minor differences. Firstly, the share of medium-technology manufactures in the total imports of Brazil had started to decrease but has ticked up since 1984, returning to levels similar to those observed in the 1970s. Secondly, the share of primary products in Brazilian imports has fallen since the second oil crisis and the debt crisis of mid-1980s; meanwhile the share of primary products in the total imports of the Republic of Korea has increased since 1996. 
Figure 10

Share of imports by technological intensity, 1962-2009

(Percentages)

\section{A. Brazil}

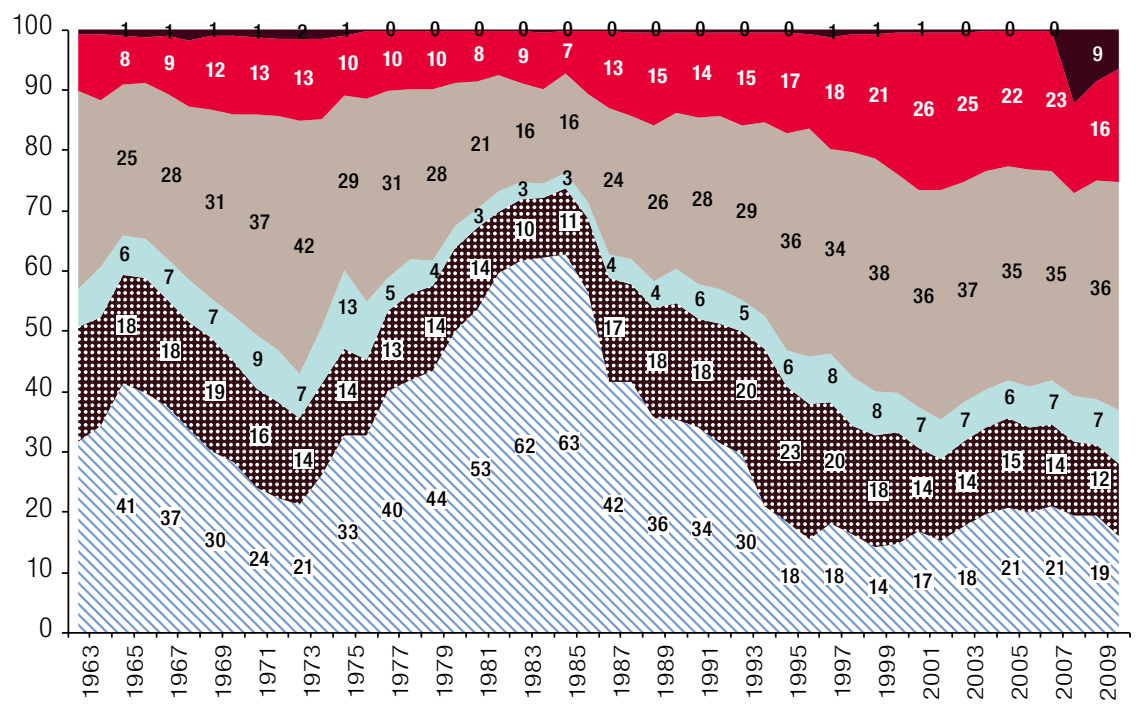

B. The Republic of Korea

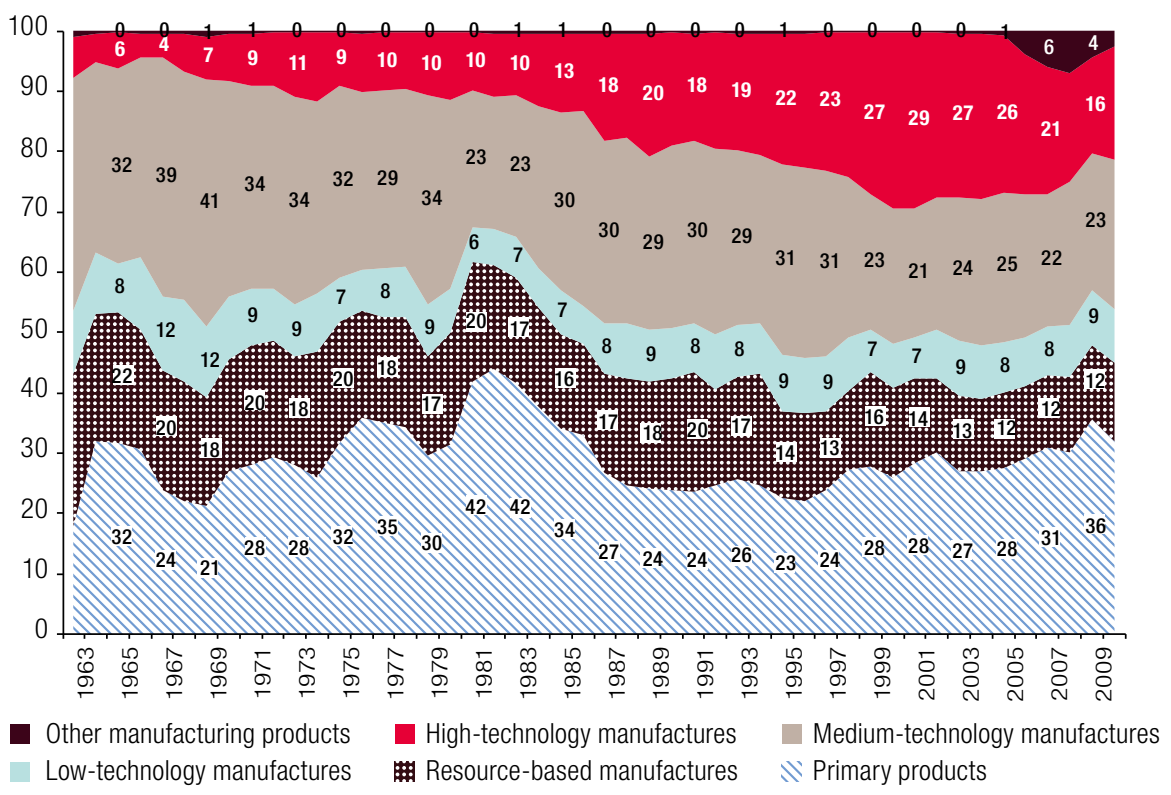

Source: Prepared by the authors.

Note: Standard International Trade Classification (SITC), Revision 1, at the four-digit level was used for the whole period.

It is interesting to note that despite the fact that high-technology manufactures account for a large share of exports from the Republic of Korea, the share of imports from this sector has also been increasing. This reveals two aspects of international trade: (i) the production of high-technology manufactures has a significant degree of international interdependency, with different components being produced in different countries; and (ii) there is a tendency towards the diversification of consumption in medium- and high-technology manufactures, which has contributed to the increase of intra-industry trade. 


\section{Economic complexity indicators}

Figure 11 uses the economic sophistication (ES) index, described in equation (4), to analyse the evolution of the complexity of the economies of Brazil and the Republic of Korea. While the ES of the Republic of Korea was already much higher than Brazil's at the beginning of the period under consideration, the economies of both the Republic of Korea and Brazil went through rapid transformations between 1962 and 1975: the ES of the Republic of Korea increased from -0.01 to 1.1 and the ES of Brazil jumped from -0.45 to 0.35 . From 1975 to 1992 , the complexity of the productive structure of the Republic of Korea decreased (down to 0.58 by 1992), while that of Brazil remained virtually unchanged (0.38 in 1992). However, after 1992, the ES of the Republic of Korea started to increase rapidly once again, peaking at 1.82 in 2006, as the share of medium- and high-technology in total exports grew, up from $58 \%$ to $69 \%$ during that period (see figure 6). Meanwhile, the ES of Brazil increased slightly, reaching 0.68 by 2000 , but after that the country's level of productive complexity plummeted, down to a negative ES (-0.29) in 2008. This fall in Brazil's economic complexity of is clearly a result of the reprimarization of the economy, as described above and reflected in figure 6, which shows that the share of both primary products and resource-based manufactures in the country's exports increased from $49 \%$ to $56 \%$ during this period.

Figure 11

Brazil and the Republic of Korea: economic sophistication, 1962-2008

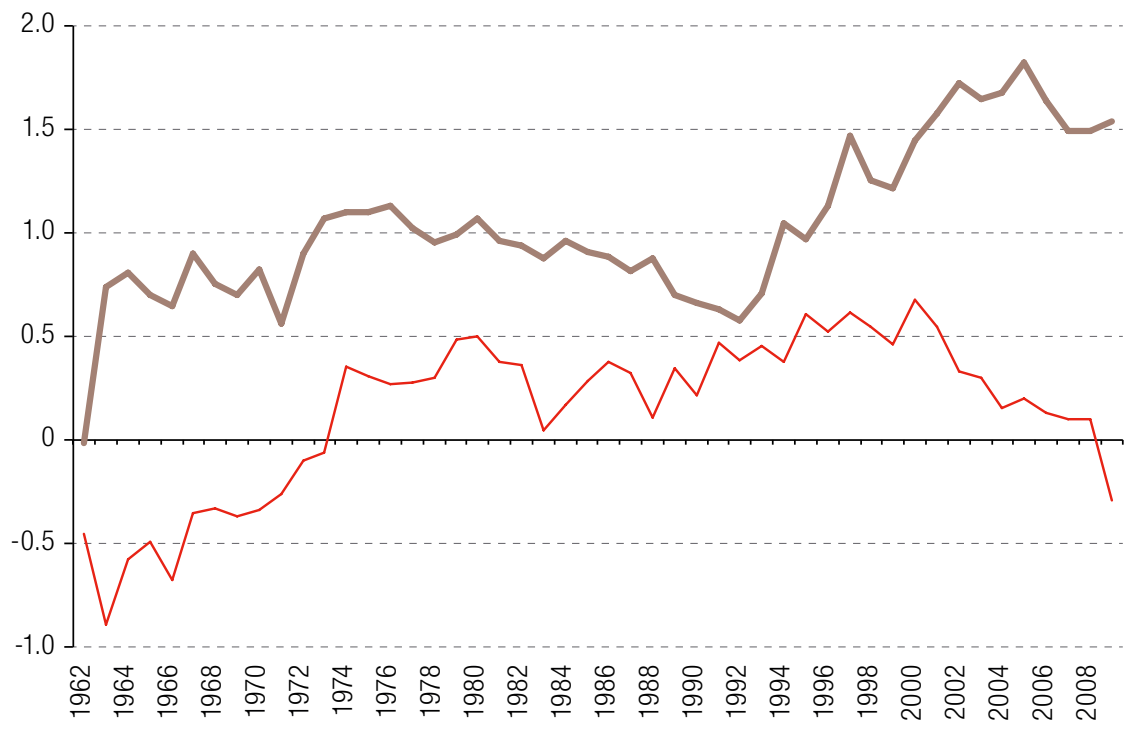

- Republic of Korea _ Brazil

Source: Prepared by the authors.

Analysis of figures 11 and 6 reveals that even moderate changes in export shares can determine a country's future development trajectory. In the case of Brazil, a 7-percentage point increase in the share of primary products and resource-based manufactures in national exports led to a considerable reduction in Brazil's economic complexity, raising concerns about the country's economic future. Meanwhile, in the Republic of Korea, exports of medium- and high-technology jumped by 11 percentage points as the economy became much more complex, which, in turn, consolidated process of income growth and structural change in that country. 
Yet, while the analyses of the evolution of diversification and bottlenecks, presented in the previous sections, are enlightening, they do not fully explain the different development paths followed by the two countries.

Together with the data on diversification and sectoral export shares (see figures 3 and 6 , respectively), one factor that should be taken into consideration when analysing the gap between the per capita GDP of the Republic of Korean and that of Brazil (see figure 1) is the difference in population size between the two countries. For the Republic of Korea, some 30 industries specializing in medium-technology manufactures with RCA and around 10 specializing in high-technology manufactures with RCA were enough to produce the impressive growth in per capita GDP. While Brazil had slightly fewer industries specializing in medium- and high-technology manufactures with RCA (some 25 and 2, respectively), its per capita GDP did not see a parallel increase. Using the ratio of medium- and high-technology manufacturing industries with RCA to total population as a basic indicator of the structural change required for development, we can see that the Republic of Korea reached a level (0.81) similar to that of developed countries, such as Canada (0.84) and the United Kingdom (0.92), while Brazil stayed on a level (0.21) closer to less developed economies, such as the Russian Federation (0.15) and the Bolivarian Republic of Venezuela (0.22).

Lastly, the structural development index is positively correlated with per capita GDP (see figure 12).

Figure 12

World: structural development index and per capita GDP, 2005 (Dollars at constant 2010 prices)

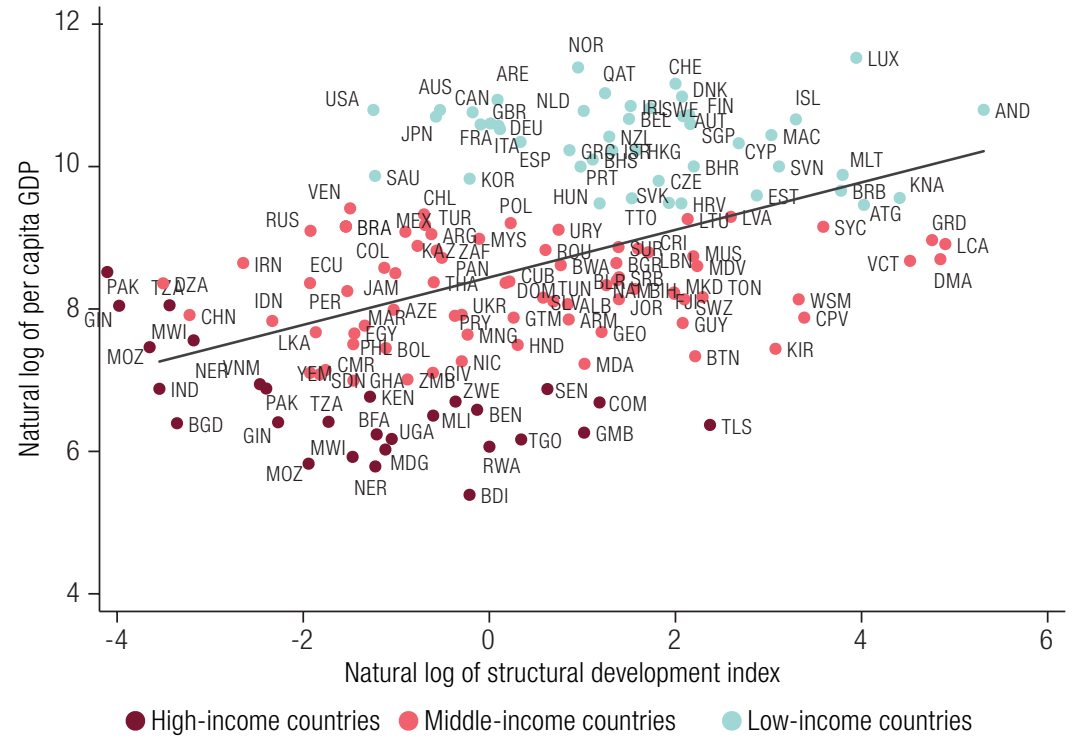

Source: Prepared by the authors.

Note: Low-income countries are those with less than US\$1,045 per capita GDP per year; medium-income countries are those with between US\$1,046 and 12,746 per capita GDP per year; high-income countries are those with over US\$12,746 per capita GDP per year.

While the ratio of the Republic of Korea was as high as those of developed countries, the size of Brazil's population required further diversification and the country's economic policies failed to foster that process. As Jacobsson (1993) highlights, the time and costs needed to learn to efficiently produce high-technology goods have been increasing over time. Consequently, further diversification in these industries becomes more and more difficult over time. 


\section{Final thoughts}

This article shows that using indices of structural development, RCA and RCD to analyse economies' diversification, bottlenecks and complexity provides important information to understand development trajectories related to structural transformations.

Taking the economic sophistication index as the main indicator of each country's product conditions, the empirical investigation presented here reveals that the development trajectories of Brazil and the Republic of Korea can be divided into three distinct periods: (i) from 1965 to 1975: the productive structure of the Republic of Korea underwent a rapid transformation, with a marked increase in the production of low-technology goods with RCA, while that of Brazil only changed slightly; (ii) from 1975 to 1995: the structural gap between the two countries narrowed, as the economy of the Republic of Korea became less diverse while the number of medium- and high-technology industries with RCA rose, and that of Brazil became more diverse while also creating more medium- and high-technology industries with RCA; (iii) from 1995 onwards: the Republic of Korea consolidated its structural transformation that fostered high economic complexity by increasing the share of medium- and high-technology manufactures in national exports, while structural changes foundered in Brazil, leading to the reprimarization of the economy, dramatically reducing its complexity.

Given that the population of Brazil is much larger than that of the Republic of Korea, more medium- and high-technology industries with RCA are needed to boost per capita GDP rates. Consequently, the costs and effort needed to learn to produce a wider variety of such goods with RCA are higher. Therefore, the data presented here indicate that the economic complexity of Brazil remained moderate, because it did not have enough medium- and high-technology industries with RCA and those industries that did exist did not account for a high enough share of exports.

The indices discussed herein can be important tools for designing more effective industrial and technological policies. Firstly, by identifying the industries with RCA, policies can focus on the areas where domestic production is more efficient. Secondly, using the product space to identify industries with high product complexity that are close to industries with RCA allows the authorities to see where they should concentrate their economic development efforts. Thirdly, the data on those industries with RCD and the potential to become exporters, on those with RCA and on the proximity between industries indicates which industries are most likely to succeed at the global level.

\section{Bibliography}

Archibugi, D. and A. Coco (2005), "Measuring technological capabilities at the country level: a survey and a menu for choice", Research Policy, vol. 34, No. 2, Amsterdam, Elsevier.

Bahar, D., R. Hausmann and C. Hidalgo (2014), "Neighbors and the evolution of the comparative advantage of nations: evidence of international knowledge diffusion?", Journal of International Economics, vol. 92, No. 1, Amsterdam, Elsevier.

Balassa, B. (1965), "Trade liberalization and revealed comparative advantage", The Manchester School, vol. 33, No. 2.

Boschma, R., P.-A. Balland and D. F. Kogler (2013), "Relatedness and technological change in cities: the rise and fall of technological knowledge in U.S. metropolitan areas from 1981 to 2010", Papers in Evolutionary Economic Geography, No. 1316, Utrecht, Utrecht University.

Burlamaqui, L., J. A. P. de Souza and N. H. Barbosa-Filho (2006), "The rise and halt of economic development in Brazil, 1945-2004: industrial catching-up, institutional innovation and financial fragility", Research Paper, No. 2006/81, Helsinki, World Institute for Development Economics Research (UNU-WIDER).

Chang, H.-J. (2006), The East Asian Development Experience. The Miracle, the Crisis and the Future, Penang, Third World Network. 
Collins, S. M. (1990), "Lessons from Korean economic growth", The American Economic Review, vol. 80, No. 2, Nashville, Tennessee, American Economic Association.

Dornbusch, R., S. Fischer and P. A. Samuelson (1977), "Comparative advantage, trade, and payments in a Ricardian model with a continuum of goods", The American Economic Review, vol. 67, No. 5, Nashville, Tennessee, American Economic Association.

Felipe, J., J. S. L. McCombie and K. Naqvi (2010), "Is Pakistan's growth rate balance-of-payments constrained? Policies and implications for development and growth", Oxford Development Studies, vol. 38, No. 4, Taylor \& Francis.

Felipe, J. and others (2013), "Why has China succeeded? And why it will continue to do so", Cambridge Journal of Economics, vol. 37, No. 4, Oxford University Press.

(2012), "Product complexity and economic development", Structural Change and Economic Dynamics, vol. 23, No. 1, Amsterdam, Elsevier.

Furtado, C. (1964), Development and Underdevelopment, Berkeley, University of California Press.

Gala, P., J. Camargo and E. Freitas (2017), "The Economic Commission for Latin America and the Caribbean (ECLAC) was right: scale-free complex networks and core-periphery patterns in world trade”, Cambridge Journal of Economics, vol. 42, No. 3, Oxford University Press.

Haggard, S. (2000), The Political Economy of the Asian Financial Crisis, Washington, D.C., Institute for International Economics.

Harvie, C. and H.-H. Lee (2003), "Export-led industrialisation and growth: Korea's economic miracle, 1962-89", Australian Economic History Review, vol. 43, No. 3, Wiley.

Hausmann, R., J. Hwang and D. Rodrik (2007), "What you export matters", Journal of Economic Growth, vol. 12, No. 1, Springer.

Hausmann, R. and C. Hidalgo (2011), "The network structure of economic output", Journal of Economic Growth, vol. 16, No. 4, Springer.

Hausmann, R. and others (2011), The Atlas of Economics Complexity: Mapping Paths to Prosperity, New York, Puritan Press.

Hidalgo, C. and R. Hausmann (2009), "The building blocks of economic complexity", Proceedings of the National Academy of Sciences of the United States of America, vol. 106, No. 26, Washington, D.C., National Academy of Sciences.

Hidalgo, C. and others (2007), "The product space conditions the development of nations", Science, vol. 317, No. 5837, Washington, D.C., American Association for the Advancement of Science.

Hirschman, A. O. (1958), The Strategy of Economic Development, New Haven, Yale University Press.

Hong, S. J., C. Jeon and J. Kim (2013), 2012 Modularization of Korea's Development Experience: The Internalization of Science and Technology in the Earlier Stage of Economic Development in South Korea [online] https://www.kdevelopedia.org/mnt/idas/asset/2013/06/17/DOC/PDF/04201306170126736076481.pdf.

Jacobsson, S. (1993), "The length of the infant industry period: evidence from the engineering industry in South Korea", World Development, vol. 21, No. 3, Amsterdam, Elsevier.

Kaldor, N. (1966), Causes of the Slow Rate of Economic Growth of the United Kingdom, London, Cambridge University Press.

Kuznets, P. (1990), "Indicative planning in Korea", Journal of Comparative Economics, vol. 14, No. 4, Amsterdam, Elsevier.

Kuznets, S. (1966), Modern Economic Growth, New Haven, Yale University Press.

Lall, S. (2000), "The technological structure and performance of developing country manufactured exports, 1985-98", Oxford Development Studies, vol. 28, No. 3, Taylor \& Francis.

_ (1992), "Technological capabilities and industrialization”, World Development, vol. 20, No. 2, Amsterdam, Elsevier.

Leamer, E. (1984), Sources of Comparative Advantage: Theory and Evidence, Cambridge, Massachusetts, The MIT Press.

Lewis, A. (1955), The Theory of Economic Growth, Homewood, Irwin.

McMillan, M. and D. Rodrik (2011), "Globalization, structural change, and productivity growth", NBER Working Paper, No. 17143, Cambridge, Massachusetts, National Bureau of Economic Research.

Netto, A. D. (2005), "Meio século de economia brasileira: desenvolvimento e restrição externa”, Economia Brasileira Contemporânea (1945-2004), F. Giambiagi and others (orgs.), Rio de Janeiro, Elsevier.

Prebisch, R. (1962), "The economic development of Latin America and its principal problems", Economic Bulletin for Latin America, vol. 7, No. 1, Santiago, United Nations. 
Romero, J. P. and G. Britto (2018), "Sophistication, productivity and trade: a sectoral investigation", Alternative Approaches in Macroeconomics, P. Arestis (eds.), Cham, Palgrave Macmillan.

Serrano, F. and R. Summa (2011), "Política macroeconômica, crescimento e distribuição de renda na economia brasileira dos anos 2000" [online] http://www.excedente.org/wp-content/uploads/2014/11/ Serrano-Summa-2011-AKB.pdf.

Woo-Cumings, M. (1999), "The state, democracy, and the reform of the corporate sector in Korea", The Politics of the Asian Economic Crisis, T. J. Pempel (ed.), Ithaca, Cornell University Press. 